\title{
Effect of meteorological factors on COVID-19 cases in Bangladesh
}

\author{
Abu Reza Md. Towfiqul Islam ${ }^{1}$ (D) - Md. Hasanuzzaman ${ }^{1}$ - Md. Abul Kalam Azad ${ }^{1}$. \\ Roquia Salam ${ }^{1} \cdot$ Farzana Zannat Toshi ${ }^{2} \cdot$ Md. Sanjid Islam Khan ${ }^{1}$. \\ G. M. Monirul Alam ${ }^{3}$. Sobhy M. Ibrahim ${ }^{4}$
}

Received: 19 August 2020 / Accepted: 26 September 2020 / Published online: 8 October 2020

(c) Springer Nature B.V. 2020

\begin{abstract}
This work is intended to examine the effects of Bangladesh's subtropical climate on coronavirus diseases 2019 (COVID-19) transmission. Secondary data for daily meteorological variables and COVID-19 cases from March 8 to May 31, 2020, were collected from the Bangladesh Meteorological Department (BMD) and Institute of Epidemiology, Disease Control and Research (IEDCR). Distributed lag nonlinear models, Pearson's correlation coefficient and wavelet transform coherence were employed to appraise the relationship between meteorological factors and COVID-19 cases. Significant coherence between meteorological variables and COVID-19 at various time-frequency bands has been identified in this work. The results showed that the minimum (MinT) and mean temperature, wind speed (WS), relative humidity $(\mathrm{RH})$ and absolute humidity $(\mathrm{AH})$ had a significant positive correlation while contact transmission had no direct association with the number of COVID-19 confirmed cases. When the MinT was $18{ }^{\circ} \mathrm{C}$, the relative risk (RR) was the highest as 1.04 (95\% CI 1.01-1.06) at lag day 11. For the WS, the highest RR was 1.03 (95\% CI 1.00-1.07) at lag day 0, when the WS was $21 \mathrm{~km} / \mathrm{h}$. When RH was $46 \%$, the highest RR was 1.00 (95\% CI 0.98-1.01) at lag day 14. When AH was $23 \mathrm{~g} / \mathrm{m}^{3}$, the highest RR was 1.05 (95\% CI 1.01-1.09) at lag day 14. We found a profound effect of meteorological factors on SARS-CoV-2 transmission. These results will assist policymakers to know the behavioral pattern of the SARS-CoV-2 virus against meteorological indicators and thus assist to devise an effective policy to fight against COVID-19 in Bangladesh.
\end{abstract}

Keywords Bangladesh $\cdot$ Meteorological variables $\cdot$ COVID-19 $\cdot$ Relative risk $\cdot R_{\mathrm{o}} \cdot$ Contact transmission

Abu Reza Md. Towfiqul Islam

towfiq_dm@brur.ac.bd

G. M. Monirul Alam

gmmonirul79@gmail.com

Extended author information available on the last page of the article 


\section{Introduction}

In the twenty-first-century era of knowledge and technology excellence, the planet was not at all ready for the unprecedented situation caused by a virus named 'COVID-19' and later in February 2020 named the Severe Acute Respiratory Syndrome Coronavirus 2 (SARSCoV-2). The novel coronavirus diseases 2019 (COVID-19) is wreaking havoc and bringing the world into a standstill exceptionally. The COVID-19-infectious virus-was first identified in Wuhan City, Hubei Province of China in late December 2019 (Li et al. 2020). This disease was not previously identified in human bodies, and therefore, World Health Organization (WHO) took some time to declare COVID-19 as an international public health emergency on January 30, 2020, and later known it as a pandemic on 11 March, 2020. There is no particular vaccination and medical treatment of COVID-19 as still (Cortegiani et al. 2020; Wu et al. 2020). By May 31, 2020, there were 6.2 million and 0.37 million numbers of confirmed cases and deaths, respectively, reported worldwide because of the COVID-19 outbreak (WHO 2020a).

There is a connection between the novel coronavirus and climate (Wacker and Holick 2013). Several scholars have found effects of climate on some infectious diseases such as influenza (Dai et al. 2018), hand-foot-mouth disease (Yu et al. 2019) and dengue fever (Lowe et al. 2018). SARS-CoV-1 transmission can be affected by many factors like the weather and climate (Casanova et al. 2010). Epidemiological research studies showed that the ambient temperature is a critical driver in the transmission and survival of coronaviruses such as MERS-CoV and SARS-CoV-1 (e.g., Casanova et al. 2010; Chan et al. 2011). Meteorological variables are commonly considered crucial factors in the outbreak of infectious diseases (e.g., Chan et al. 2011; Lu et al. 2020). Many scientists claim that meteorological variables, in addition to human-to-human transmission, are supposed to be key factors in terms of the spread out, the variability of viruses (Chan et al. 2011; Li et al. 2020).

There is still debate about whether the outbreak of SARS-CoV-2 is being impacted by meteorology compared to other seasonal viruses or not (Neher et al. 2020). Some recent cited works examined the influences of meteorological indicators on COVID-19 spread over the globe in different locations including China (Shi et al. 2020; Liu et al. 2020; Xie and Zhu 2020; Ma et al. 2020), Iran (Ahmadi et al. 2020), Spain (Briz-Redón and SerranoAroca 2020), the USA (Bashir et al. 2020; Runkle et al. 2020), Mexico (Méndez-Arriaga 2020), Turkey (Sahin 2020), Brazil (Auler et al. 2020; Prata et al. 2020), Indonesia (Tosepu et al. 2020), Singapore (Pani et al. 2020); Norway (Menebo 2020) and also global scale (Sobral et al. 2020; Wu et al. 2020). Moreover, the environmental factors drive the patterns of COVID-19 and found a relationship with meteorological indicators (Chen et al. 2020; Sajadi et al. 2020; Luo et al. 2013). Published cited studies on COVID-19 have agreed that meteorological conditions may influence the COVID-19 outbreak (e.g., Liu et al. 2020; Xie and Zhu 2020; Tobías and Molina 2020). In addition to this, the WHO also reported that more robust research works are needed to develop predicting models and to implement local health policies. Thus, a comprehensive study of COVID-19's meteorology dependency in various regions or cities is imperative to upsurge the current insights into its outbreak.

Bangladesh is a well-known climate-vulnerable country due to its high population density and complex meteorological settings (Rahman and Islam 2019). The first three cases of pandemic COVID-19 were confirmed on March 8, 2020, in the country (IEDCR 2020). As of May 31, the number of cases reported was 47,153 and recoveries were 9781 in 62 districts out of 64 administrative districts and caused the death of 650 (IERDC 2020) (Fig. 1). 
Bangladesh had exhibited lockdown measures to suppress COVID-19, but inadequate testing and lack of monitoring home quarantine and isolation measures for overseas travelers elevated confirmed positive cases, and those in contact transmission with them (Bodrud-Doza et al.

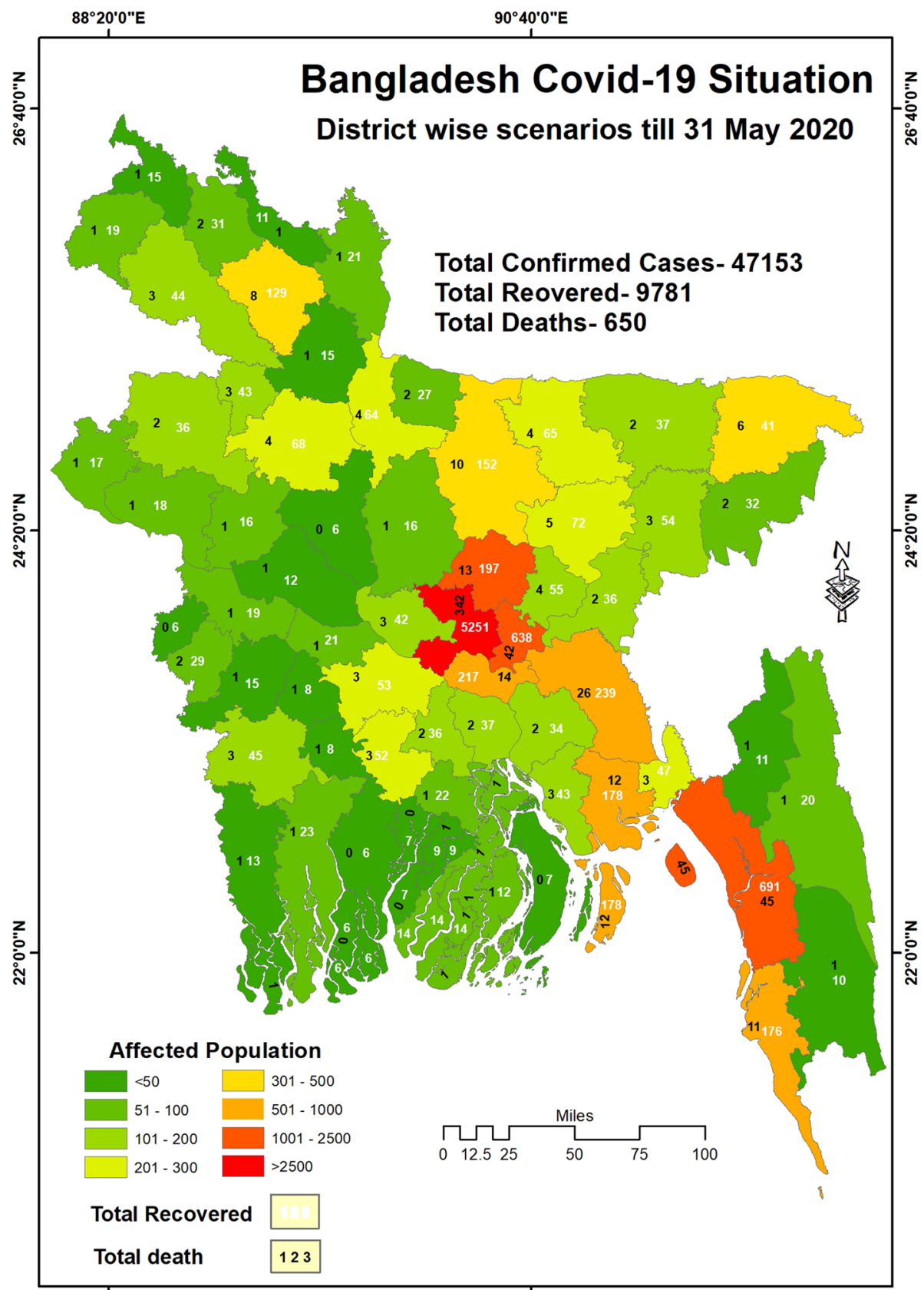

$8^{\circ} 20^{\prime} 0 " \mathrm{E}$

$90^{\circ} 40^{\prime} 0 " \mathrm{E}$

Fig. 1 Map showing the number of confirmed positive cases due to COVID-19 outbreak in Bangladesh 
2020). Because of the high dense population in South Asia, the confirmed positive cases are growing rapidly in Bangladesh which is similar to India and Pakistan. However, the nexus among meteorological indicators is not yet evident for COVID-19 confirmed cases in Bangladesh. This study intends to close this research gap. Studies on the seasonality and effect of meteorological indicators on COVID- 19, such as temperature, wind speed, humidity and air pressure, can be employed to know the timing of early interventions to alleviate SARS-CoV-2 transmission at the regional and national levels to safeguard myriad lives and resources.

As coronavirus can travel a certain distance through the air and can sustain in the air form a long time, there will be a sure influence of the meteorological factors over the transmission intensity of COVID- 19. Contact transmission is the only process the virus affects one from another as the virus contagious only from droplets. Contact transmission refers to how many populations are likely affected by a single COVID-19 patient in a given environment. Many scientists determine how contagious a disease by its eligibility of reproduction which is referred by $R_{\mathrm{o}}$ (R naught by pronunciation, reproduction factor) (Zhang et al. 2020; Sahafizadeh and Sartoli 2020; Zhao et al. 2020; Wu et al. 2020). It indicates how many people a single infected person will infect. For example, influenza has $R_{\mathrm{o}}$ of 1.3 , which means 1 infected person can infect 1.3 other persons. On the other hand, measles has a higher $R_{\mathrm{o}}$ value of 12 to $\mathrm{q} 8$, which means it is highly infectious and rapidly speared out possibilities. Contact transmission and $R_{\mathrm{o}}$ give the idea of transmission intensity in a specific area. Although the result can vary due to some factors like test quantities, how strictly quarantine and isolation are maintained, government approaches like lockdown, curfew, etc. to control the transmission. For example, in a given month if in a certain under curfew and strictly lockdown for only seven days, then the contract transmission will be increased in the second week due to lack of procedures. As a result, the $R_{\mathrm{o}}$ will increase and different from the constant result. However, in our study, we consider the period under proper lockdown, which indicates the population of other factors. The outcome reflects the actual scenarios of contact transmission and reproduction in the proposed study. In this research, we have taken into account the contact transmission $R_{\mathrm{o}}$ in the spreading of the COVID-19 pandemic. Though many regulating factors exist, the aim of this work mainly examines the effects of meteorological factors on the spread of COVID-19 in Bangladesh.

Unlike other studies, this work is motivated to raise the following issues: Is there any relationship with meteorological variables and COVID-19? If so, which climatic indicator influences the COVID-19 outbreak? Is there any relationship between contact transmission and COVID-19 after implementing social distancing? How do the time-frequency resolutions of COVID-19 cases and climatic variables are associated temporally over Bangladesh? By solving these issues, we used a robust distributed log nonlinear model (DLNMs) and the wavelet transform coherence methods to understand the influence of meteorological indicators on the spread of SARS-CoV-2. The knowledge added the meteorological factors on COVID-19 that can be combined with other interventions associated with human contact transmission factors that boost immunity against meteorological factors to reduce outbreaks.

\section{Data and methods}

\subsection{Study area}

Bangladesh is situated in Southeast Asia. There are three main seasons shown in this country, which are post-monsoon, monsoon and the pre-monsoon. There are seven climatic sub-regions in Bangladesh that are: (1) southeastern region; (2) northeastern region; (3) 
northern region; (4) northwestern region; (5) western region; (6) southwestern region; and (7) south central region (Islam et al. 2018). Here, monsoon is probably the controlling feature of climatic variability (Rahman and Islam 2019). Most of the rainfall (more than 50\%) recorded in this season. Mean maximum temperature, minimum temperature and relative humidity across the country are $29.94{ }^{\circ} \mathrm{C}, 21.39{ }^{\circ} \mathrm{C}$, and $80 \%$, respectively.

\subsection{Data sources}

The major meteorological variables including daily minimum temperature $\left({ }^{\circ} \mathrm{C}\right)$, maximum temperature $\left({ }^{\circ} \mathrm{C}\right)$, relative humidity $(\%)$ datasets of 43 stations are demarcated into seven climatic regions from March 08 to May 31, 2020, which were collected from the Bangladesh Meteorological Department (BMD). The quality control of the datasets was carried out by the staff of the BMD. The remaining data such as wind speed $(\mathrm{km} / \mathrm{s})$ and air pressure (mbar) were obtained from the following Web site (https://www.timeanddate.com). Mean and diurnal temperature $\left({ }^{\circ} \mathrm{C}\right)$ datasets were calculated from the minimum temperature and maximum temperature. There were no missing data in the climatic datasets of May 2020. Data of the COVID-19 confirmed cases per day in Bangladesh from March 08 to May 31, 2020, were collected from the Institute of Epidemiology Disease Control and Research (IEDCR 2020).

Contact transmission data were computed based on previous scenario studies through $R_{\mathrm{o}}$ values ( $\mathrm{R}$ naught/reproduction factor). In this study, we calculated the simple changes in the number of affected persons in a 14-days period for instance CT1 (the first period), CT2 (Second period) and CT3 (third period), respectively. It is noted that coronavirus takes a maximum of 14-days to result in positive. Our observation period was 45 days, 3 phases of 15 days (COVID-19 symptoms take 5 to 14 days to show up), respectively. We compare the estimated data to the acceptable range of $R_{\mathrm{o}}$ which we assumed as 2 to 2.5 and determine based on the scenario of contact transmission.

\subsection{Calculation procedure of absolute humidity}

The absolute humidity (AH) is computed by Eq. 1 (Snyder 2005):

$$
\mathrm{AH}=\frac{2165 e}{T_{\text {mean }}+273.16}
$$

where $\mathrm{AH}$ is the absolute humidity $\left(\mathrm{g} / \mathrm{m}^{3}\right)$, e is vapor pressure $(\mathrm{KPa})$ and Tmean is the average temperature $\left({ }^{\circ} \mathrm{C}\right)$. The detailed procedure of calculating vapor pressure can be found in the paper of Snyder (2005).

\subsection{Distributed lag nonlinear Model (DLNM)}

To analyze the exposure-lag-response curve between climatic factors and daily confirmed cases of COVID-19, we applied a distributed lag nonlinear model. This model was previously used in several studies (Lu et al. 2020; Runkle et al. 2020; Shi et al. 2020). Here, we used a quasi-Poisson lag-based DLNM model to explore the relationship of MaxT, MinT, DT, WS, RH and AH with COVID-19 confirmed cases. Here we excluded AP and MT due to their lower correlation value. We have considered the country average of the climatic factors by averaging the values of seven climatic regions. Equation 2 is expressed in the following way: 


$$
\log \left[E\left(Y_{t}\right)\right]=\alpha+\sum \mathrm{NS}_{i}\left(X_{i}, d f\right)+\delta \mathrm{DOW}
$$

$Y_{t}$ represents the observed daily cases of COVID-19 in day $t ; \alpha$ and $\delta$ both are the intercepts; NS is the abbreviation of natural cubic spline; $X$ is climatic variables, such as MaxT, MinT, DT, WS, RH and AH; $d f$ represents the degree of freedom; based on the AICs, we choose $d f=3$ for NS to the climatic factors. Here, as this study obtains a short-term trend period, so we did not consider the cubic spline on time, which is used to control long-term trends, seasonality and climatic variables. The main justification for using DLNM is that it allows a broader representation of the time course of the exposure-response relationship. This gives an estimate of the overall effect in the presence of delayed contributions or harvesting. It can simultaneously represent nonlinear exposure-response dependencies and delayed effects (Gasparrini et al. 2010).

It is found that the COVID-19 incubation period between exposure and symptom occurrence took time 2 to 14 days (Linton et al. 2020); thus, we used a maximum of 14-day lag in our study as Runkle et al. (2020).

\subsection{Wavelet transform coherence and partial wavelet coherence}

Wavelet transform coherence (WTC) and partial wavelet coherence (PWC) were used in this study for obtaining the expressions of time and frequency resolutions of climatic variables and COVID-19 cases in Bangladesh. WTC quantifies the covariance magnitude between two time series which vary from 0 to $1\left(0 \leq R^{2} \leq 1\right)$. 0 refers to no coherence at all, whereas 1 refers to perfect coherence. This range is defined as the cross-spectrum normalized square by the smoothed individual power spectrum. As the coherence becomes greater, the symphony between two time series increases and the coherence between the two time series can simply be defined by Eq. 3:

$$
R^{2}(m, n)=\frac{\mid N\left(\left.N^{-1} W_{x y}(m, n)\right|^{2}\right.}{N\left(N ^ { - 1 } | W _ { x } ( m , n ) | ^ { 2 } N \left(N^{-1}\left|W_{y}(m, n)\right|^{2}\right.\right.}
$$

Wavelet can give the short-term, medium-term as well as long-term relationship between two variables (Iqbal et al. 2020).

Partial wavelet coherence (PWC) comprises three time series in which coherence was estimated between two of the series while the common influences of the third series are minimized. The statistical expression of partial wavelet coherence is given by Eqs. 4-9:

$$
\begin{aligned}
& R\left(x_{1}, x_{2}\right)=\frac{S\left[W\left(x_{1}, x_{2}\right)\right]}{\sqrt{S\left[W\left(x_{1}\right)\right]} S\left[W\left(x_{2}\right)\right]} \\
& R^{2}\left(x_{1}, x_{2}\right)=R\left(x_{1}, x_{2}\right) \cdot R\left(x_{1}, x_{2}\right) \\
& R\left(x_{1}, y\right)=\frac{S\left[W\left(x_{1}, y\right)\right]}{\sqrt{S\left[W\left(x_{1}\right)\right] S[W(y)]}}
\end{aligned}
$$




$$
\begin{aligned}
& R^{2}\left(x_{1}, y\right)=R\left(x_{1}, y\right) \cdot R\left(x_{1}, y\right) \\
& R\left(x_{2}, y\right)=\frac{S\left[W\left(x_{2}, y\right)\right]}{\sqrt{S\left[W\left(x_{2}\right)\right] S[W(y)]}} \\
& R^{2}\left(x_{2}, y\right)=R\left(x_{2}, y\right) \cdot R\left(x_{2}, y\right)
\end{aligned}
$$

In this study, we use the wavelet analysis because it can offer a simultaneous localization in time and frequency domains. Wavelet theory is capable of revealing aspects of data that other signal analysis techniques miss such as trends, breakdown points, and discontinuities in higher derivatives and self-similarity. Since datasets were not normally distributed, the Pearson correlation coefficient was employed to explore the association between climatic variables and COVID-19 confirmed cases. The relationship between daily confirmed cases and meteorological variables in the COVID-19 outbreak in seven climatic regions of Bangladesh from March 8 to May 31, 2020, was explored using locally weighted regression and smoothing scatterplot (LOESS) followed by Shi et al. (2020). LOESS plot uses in our work due to its simplicity which does not require the specification of a function to fit a model to all the data in the sample.

\section{Results}

\subsection{Descriptive statistics}

From March 8 to May 31, 2020, the reported numbers of total confirmed cases, death and recovery cases of COVID-19 in seven climatic regions over Bangladesh were 47,153, 650 and 9781. Figure 2 shows the daily counts of COVID-19 positive cases, from March 8 to May 31, 2020, in these climatic regions. The confirmed case of SARS-CoV-2 transmission in Bangladesh was first reported on March 8, 2020 (https://www.iedcr.gov.bd/). Although officially lockdown in the country was started on March 25 to reduce the further outbreak of COVID-19 (https://www.iedcr.gov.bd), data demonstrated a sharp rise simultaneously in new positive confirmed cases from April 10, 2020, onward to reach the peak on May 31, 2020, in Bangladesh (Fig. 2). Most of the COVID-19 confirmed cases found in the south central region, followed by the southeastern region.

Table 1 reveals a statistical summary of the daily number of COVID-19 positive cases, geographic and weather variables in Bangladesh. On average, there were 554.7 \pm 660.3 numbers of positive confirmed cases of COVID-19 per day. The rate of infection and days of infection was $8.5 \pm 8.4$ and $38.9 \pm 16.2$ on average, respectively, due to the low rate of testing in Bangladesh.

The temperatures $(T)$ ranged from 23.5 to $31.6{ }^{\circ} \mathrm{C}$ with an average of $27.6 \pm 1.7{ }^{\circ} \mathrm{C}$, and DTR was an average of $8 \pm 9.2{ }^{\circ} \mathrm{C}$. The wind speed (WS) ranged from 1.93 to $21.71 \mathrm{~km} / \mathrm{h}$ with an average of $5.3 \pm 3.7 \mathrm{~km} / \mathrm{h}$ during the observation period. The relative humidity $(\mathrm{RH})$ mostly relies on the temperature and air pressure of the atmosphere. The air pressure (AP) values ranged from 1000.2 to 1013.9 mbar with a mean of $1009.8 \pm 2.9$ mbar. The relative humidity (RH) and absolute humidity (AH) were $36.00-81.25 \%$ and $9.18-20.99 \mathrm{~g} / \mathrm{m}^{3}$ with a mean of $65.5 \pm 9 \%$, and $16.6 \pm 2.8 \mathrm{~g} / \mathrm{m}^{3}$, respectively. The contact transmission (CT1) is high 


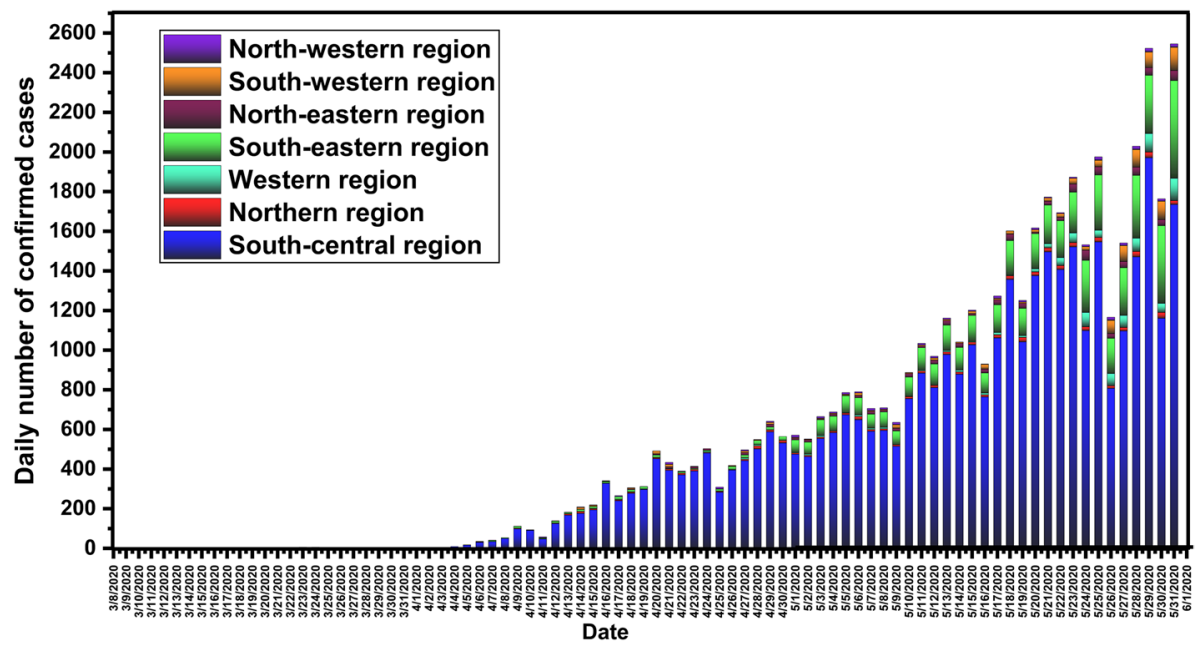

Fig. 2 Daily number of positive cases of the COVID-19 in seven climatic regions over Bangladesh between March 08 and May 31, 2020

Table 1 Descriptive statistics of meteorological variables and contact transmission (March 8-May 31, 2020; $N=81$ ) over Bangladesh

\begin{tabular}{lrrrrrrr}
\hline Parameters & Mean \pm STD & Median & Minimum & Maximum & P 25 & P 50 & P 75 \\
\hline Max temp. $\left({ }^{\circ} \mathrm{C}\right)$ & $31.6 \pm 1.9$ & 31.7 & 26.8 & 34.9 & 30.5 & 31.7 & 33.0 \\
Min temp. $\left({ }^{\circ} \mathrm{C}\right)$ & $23.5 \pm 3.1$ & 23.1 & 17.3 & 29.3 & 21.0 & 23.1 & 26.1 \\
Diurnal temp. $\left({ }^{\circ} \mathrm{C}\right)$ & $8 \pm 9.2$ & 9.2 & 1.1 & 14.8 & 3.8 & 9.2 & 11.6 \\
Mean temp. $\left({ }^{\circ} \mathrm{C}\right)$ & $27.6 \pm 1.7$ & 27.5 & 23.6 & 31.1 & 26.3 & 27.5 & 28.7 \\
Wind speed $(\mathrm{Km} / \mathrm{h})$ & $5.3 \pm 3.7$ & 4.2 & 1.9 & 21.7 & 3.5 & 4.2 & 5.4 \\
Air pressure $(\mathrm{mbar})$ & $1009.8 \pm 2.9$ & 1010.4 & 1000.2 & 1013.9 & 1008.6 & 1010.4 & 1011.8 \\
Relative humidity $(\%)$ & $65.5 \pm 9$ & 66.6 & 36.0 & 81.3 & 60.2 & 66.6 & 72.0 \\
Absolute humidity $\left(\mathrm{g} / \mathrm{m}^{3}\right)$ & $16.6 \pm 2.8$ & 17.0 & 9.2 & 21.0 & 15.1 & 17.0 & 18.8 \\
Confirmed cases & $554.7 \pm 660.3$ & 312.0 & 0.0 & 2545.0 & 4.0 & 312.0 & 908.5 \\
Contact transmission 1 $(\mathrm{CT} 1)$ & $5.3 \pm 2.4$ & 4.8 & 3.4 & 9.7 & 3.5 & 4.8 & 7.3 \\
Contact transmission 2 $(\mathrm{CT} 2)$ & $3.1 \pm 1.4$ & 2.8 & 2.0 & 6.1 & 2.1 & 2.8 & 3.5 \\
Contact transmission 3 (CT3) & $3 \pm 1.5$ & 2.6 & 1.8 & 6.1 & 2.0 & 2.6 & 3.5 \\
\hline
\end{tabular}

as 3.4 and low as 9.7 with a mean of $5.3 \pm 2.4$ per confirmed COVID-19 positive case until May 1, 2020. The contact transmission (CT2) is high as 2.0 and low as 6.1, with a mean of $3.1 \pm 1.4$ until May 15, 2020, which was comparatively low transmission than CT1. The contact transmission (CT3) was varied between 1.8 and 6.1 with a mean of $3 \pm 1.5$ till May 29 , 2020, which is also relatively low CT than CT1 and CT2.

Table 2 shows the monthly variations in various climatic variables in Bangladesh. The comparatively high variations in $\mathrm{RH}, \mathrm{AH}, \mathrm{AP}$ and WS were observed compared to other meteorological variables. The highest RH was detected in May $(71 \pm 4 \%)$. WS was the highest in May $(7.3 \pm 5.4 \mathrm{~km} / \mathrm{h})$ and the lowest in March $(3.8 \pm 1.3 \mathrm{~km} / \mathrm{h})$. AP is highly variable and exhibits a declining trend from March to May. Consequently, the MinT showed 
Table 2 Monthly changes in the SARS-CoV-2 and meteorological variables $($ mean $\pm S D)$ in Bangladesh

\begin{tabular}{|c|c|c|c|c|c|c|}
\hline \multirow[t]{2}{*}{ Variables } & \multicolumn{2}{|l|}{ March } & \multicolumn{2}{|l|}{ April } & \multicolumn{2}{|l|}{ May } \\
\hline & Mean & STD & Mean & STD & Mean & STD \\
\hline Max temp. & 32.1 & 1.6 & 32.6 & 1.5 & 30.2 & 1.8 \\
\hline Min temp. & 20.3 & 1.4 & 22.8 & 1.3 & 26.8 & 1.9 \\
\hline Diurnal temp. & 11.8 & 1.2 & 9.8 & 2.0 & 3.4 & 1.1 \\
\hline Average temp. & 26.2 & 1.4 & 27.7 & 1.0 & 28.5 & 1.7 \\
\hline Wind speed & 3.8 & 1.3 & 4.5 & 1.3 & 7.3 & 5.4 \\
\hline Air pressure & 1011.4 & 1.8 & 1009.4 & 2.8 & 1009.0 & 3.1 \\
\hline Relative humidity & 55.9 & 8.7 & 67.7 & 6.9 & 71.0 & 4.0 \\
\hline Absolute humidity & 13.7 & 2.0 & 18.2 & 2.4 & 19.9 & 2.1 \\
\hline
\end{tabular}

an increasing trend during the study period. These might be a reason for the elevated infections in May (Table 2).

The association between COVID-19 cases and climatic factors including all seven climatic regions is shown as LOESS plots in Fig. 3. Due to the highest confirmed cases, south central region shows the most expressive result where all other regions show a flat curve except for the southeastern region. COVID-19 confirmed cases increase with the increase in MinT, WS, RH and AH in the south central region. The highest temperature, wind speed,
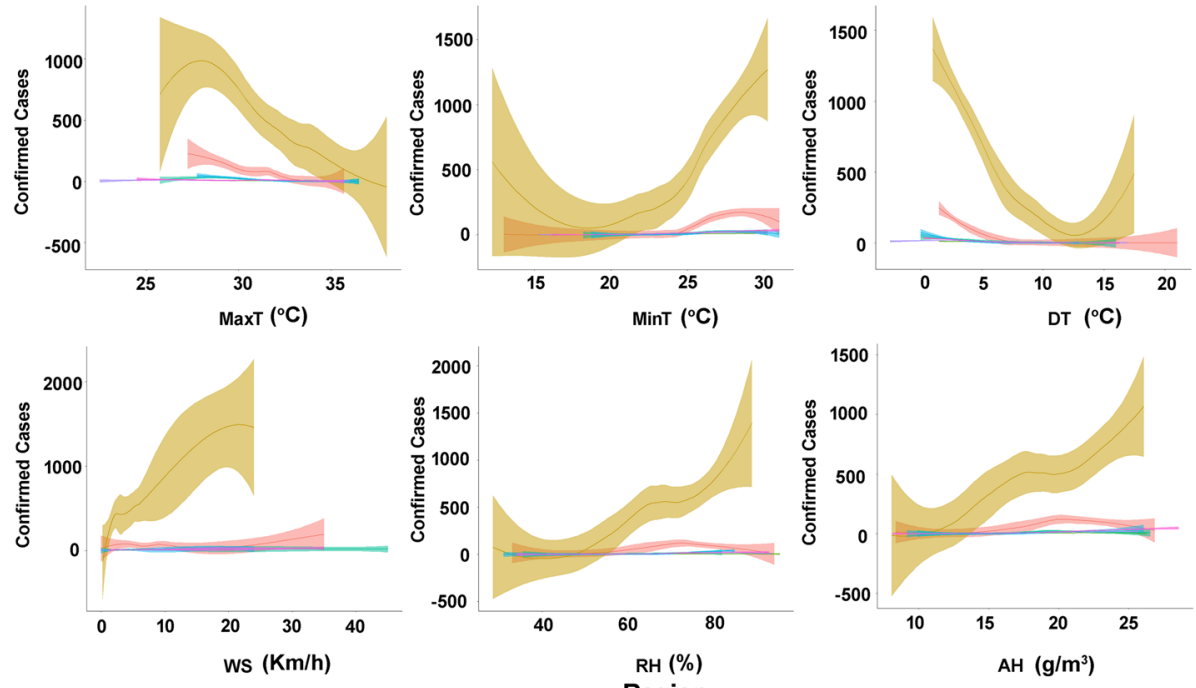

South-eastern region

South-central region

North-western region

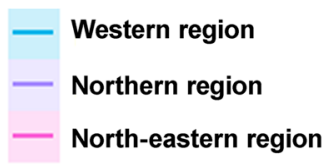

South-western region

Fig. 3 COVID-19 daily confirmed cases and the expected values based on the maximum temperature (MaxT), minimum temperature (MinT), diurnal temperature (DT), wind speed (WS), relative humidity (RH) and absolute humidity $(\mathrm{AH})$ in seven climatic regions of Bangladesh from March 08 to May 31, 2020, respectively. The green line represents the expected value of a daily confirmed case based upon a LOESS regression for all days of available estimates. LOESS, locally weighted regression and smoothing scatter plots 
relative and absolute humidity of this region were found $38{ }^{\circ} \mathrm{C}, 24 \mathrm{~km} / \mathrm{h}, 89 \%$ and $26.1 \mathrm{~g} /$ $\mathrm{m}^{3}$, respectively. On the other hand, the lowest values were found to be $12.3{ }^{\circ} \mathrm{C}, 0.3 \mathrm{~km} / \mathrm{h}$, $28.5 \%$ and $8.1 \mathrm{~g} / \mathrm{m}^{3}$. After $27.7^{\circ} \mathrm{C}$, the MaxT the confirmed cases sharply reduced where for MinT the trend goes sharply upward after $18.3{ }^{\circ} \mathrm{C}$. As for DT, the number of cases decreased initially, but after $12.3{ }^{\circ} \mathrm{C}$ the number increased with a sharp trend. WS, RH and $\mathrm{AH}$ had an upward trend from the initial stage.

\subsection{Association between meteorological indicators and COVID-19 infected cases}

The first cases of COVID-19 outbreak were reported on March 8, 2020; thus, the daily data (both meteorological indicators and COVID-19 pandemic) from March 8 to May 31, 2020, were employed for the correlation analysis. Table 3 outlines the results of Pearson's correlation test. MT and MinT exhibited significant positive associations with the COVID-19 confirmed cases over the study area (Table 3). However, there was no direct association between contact transmission (CT1, CT2 and CT3) and SARS-CoV-2 virus over Bangladesh during the observation period. By contrast, MaxT and DT showed strong inverse associations in the case of May 31 dataset.

RH showed a strong positive significant association with COVID-19 cases over Singapore (Table 3). This implies that the maximum RH $(71.4 \pm 4 \%)$ in May favored the COVID-19 spread. WS showed a significant association with COVID-19 confirmed cases in Bangladesh (Table 3). However, AP showed comparatively strong inverse relationships with COVID-19 infected positive cases in Bangladesh during the initial phase of the SARS-CoV-2 outbreak. On the whole, high values of MinT, RH and AH along with low WS during May (Table 2) intensified the SARS-CoV-2 spread.

\subsection{Effect of meteorological indicators on COVID-19 transmission}

Figure 4 of 3-dimensional plots displays the relationship between meteorological variables and COVID-19 confirmed cases in different lag days in Bangladesh. Various characteristics were found in various meteorological variables with a nonlinear curve. Figure 4 shows that the highest risk was found 0.99 (95\% CI 0.70-1.40) at lag 14 when the MaxT was 27o C. As for MinT was $18{ }^{\circ} \mathrm{C}$, the highest risk was found 2.2 (95\% CI 0.0003-15,878.36) at lag 0 . When DT was $4{ }^{\circ} \mathrm{C}$ at lag day 14 , the RR was highest 1.46 (95\% CI 1.18-1.80). When WS was $21 \mathrm{~km} / \mathrm{h}$ at lag day 0 , the RR was highest at 0.65 (95\% CI 0.30-1.39). As for RH, the highest risk was found at 2.31 (95\% CI 0.82-6.56) at lag 14 when the $\mathrm{RH}$ was $46 \%$. AH has the highest risk of 2.29 (95\% CI 0.93-5.66) at lag 14 when the value was $23 \mathrm{~g} / \mathrm{m}^{3}$.

We represented the lag-response relationship for the 1-unit increase in all meteorological indicators in different lag days (up to 14-day) (Fig. 5). The highest RR of MaxT was found 1.00 (95\% CI 0.99-1.01) in lag 6 where the lowest value was found 0.92 (95\% CI 0.88-0.95) in lag 0. The greatest RR of MinT was found to be 1.04 (95\% CI 1.01-1.06) in lag 11, while the lowest was 1.01 (95\% CI 0.99-1.02) in lag 2. For DT and WS, the highest RR was 0.97 (95\% CI 0.97-0.98) and 1.03 (95\% CI 1.00-1.07) in lag 8 and 0, respectively. Also, both DT and WS had the lowest association of 0.95 (95\% CI 0.92-0.99) and 1.00 (95\% CI 0.99-1.02) in lag 0 and 4, respectively. $\mathrm{RH}$ and $\mathrm{AH}$ had the highest association of lag response curve in lag 14 [1.00 (95\% CI 0.98-1.01); 1.05 (95\% CI 1.01-1.09)] where the lowest RR was found for these 3 variables [0.96 (95\% CI 0.94-0.98); 0.94 (95\% CI 0.90-0.98)] in lag 0.

We depicted unidimensional curves regarding the cumulative effects of meteorological indicators along various lag days (Fig. 6). MinT and WS were positively related to the 


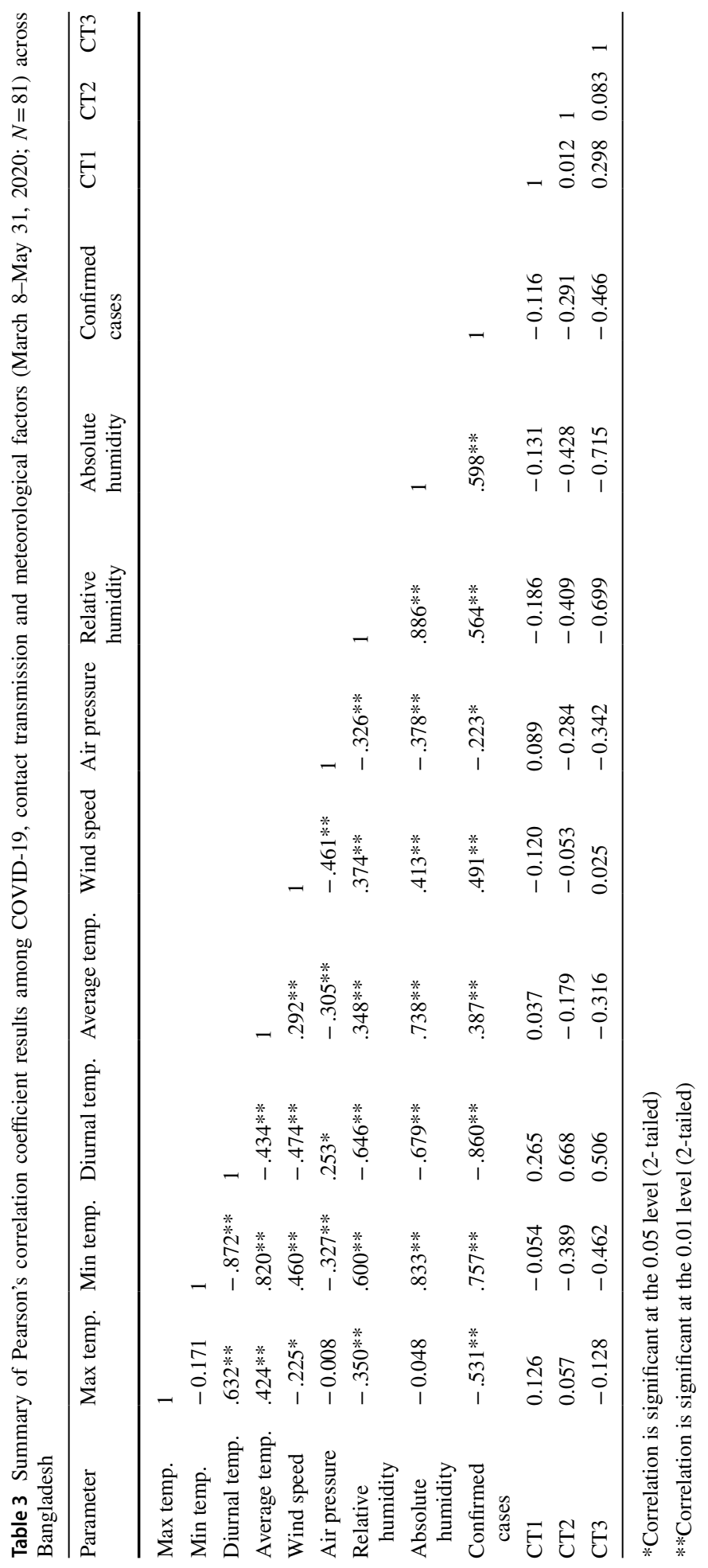



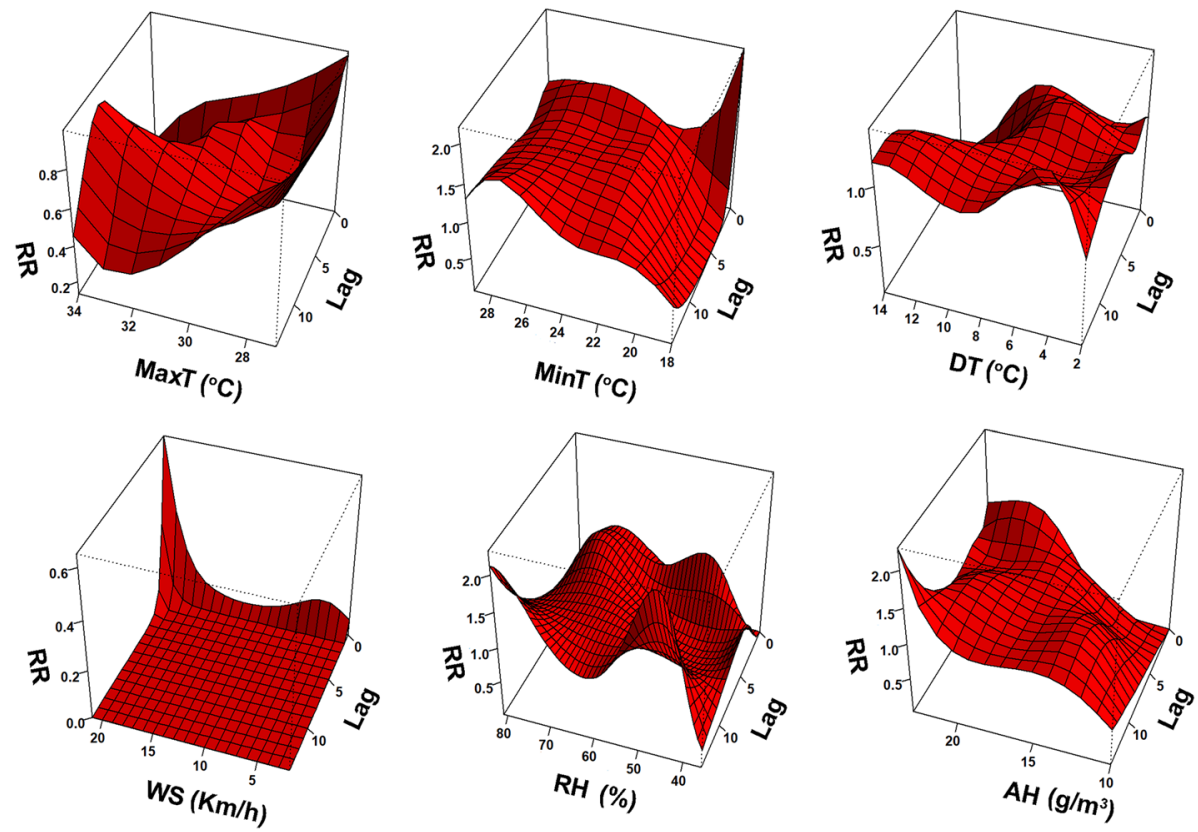

Fig. 4 3-dimensional plots of the relative risk of climatic factors on SARs-CoV-2 cases including maximum temperature (MaxT), minimum temperature (MinT), diurnal temperature (DT), wind speed (WS), relative humidity $(\mathrm{RH})$ and absolute humidity $(\mathrm{AH})$

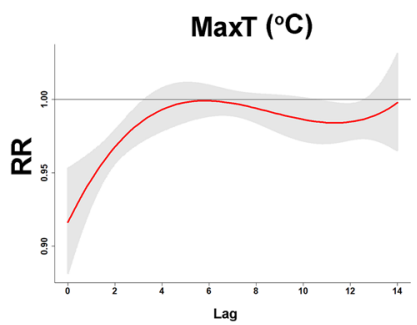

WS $(\mathrm{Km} / \mathrm{h})$

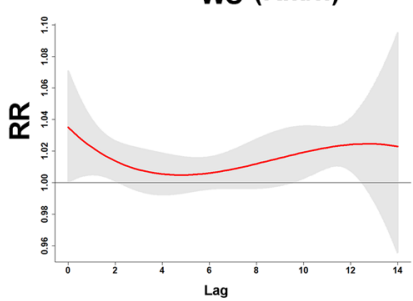

$\operatorname{MinT}\left({ }^{\circ} \mathrm{C}\right)$

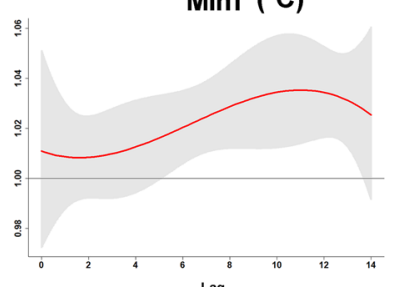

RH (\%)
DT ( $\left.{ }^{\circ} \mathrm{C}\right)$

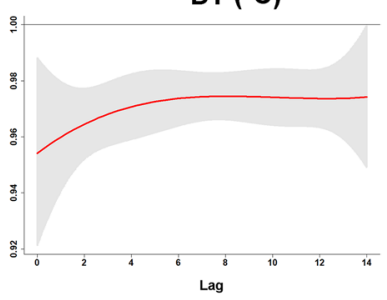

AH $\left(g / m^{3}\right)$
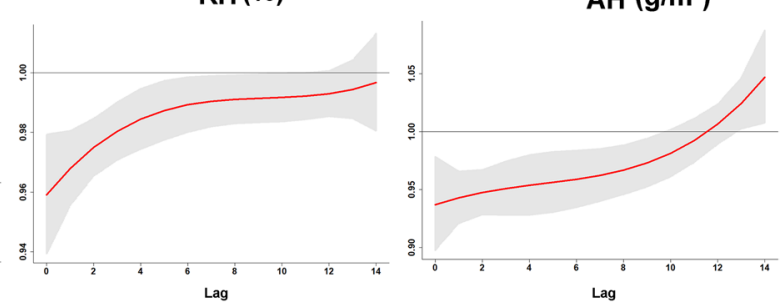

Fig. 5 Single effects of MaxT, MinT, DT, WS, RH and AH. The Y lab denotes the value of relative risk (RR); the X lab indicates the value of relevant parameters. The red lines denote mean RR, and the gray regions represent $95 \%$ CIs. The black vertical line indicates the medians of the climatic variables, respectively 
COVID-10 transmission, which was the opposing to MaxT, and DT. Figure 6 displays the incremental cumulative effects of meteorological variables in 14 lag days. The highest RR of MaxT, DT and RH was found [0.92 (95\% CI 0.88-0.95); 0.95 (95\% CI 0.92-0.99); 0.96 (95\% CI 0.94-0.98)], respectively, in lag 0 where the lowest RR was found in [0.76 (95\% CI 0.70-0.81); 0.64 (95\% CI 0.59-0.68); 0.80 (95\% CI 0.72-0.90)] consecutively in lag 14. MinT had the highest RR 1.39 (95\% CI 1.29-1.49) in lag 14, while the lowest association was found 1.01 (95\% CI 0.97-1.05) in lag 0. The greatest RR of WS was found to be 1.27 (95\% CI 1.09-1.50) in lag 14 while the lowest was 1.03 (95\% CI 1.00-1.07) in lag 0. As for $\mathrm{AH}$, the highest and lowest RR values were found to be 0.94 (95\% CI 0.90-0.98) and 0.61 (95\% CI 0.50-0.75) in lag 0 and 11 , respectively.

\subsection{Nexus between meteorological factors and number of COVID-19 cases}

We have used wavelet transform coherence (WTC) to inquire about the association of the time-frequency band between COVID-19 confirmed cases and climatic parameters. The vertical direction represents the period, the horizontal direction represents the date scale, and the red hot region represents the coherence of a significant period (Fig. 7). WTC between COVID-19 and MaxT (Fig. 7a) exhibited significant coherence within the 0-4 and 4-8 frequency bands. The most significant coherence occurred within the frequency band of 4-8, correlating 0.8 during April 11-April 30. The phase angle indicated that the two signals were having an in-phase relationship approximately during that period. WTC between COVID-19 and MinT elicited multiple bands of coherence within the $0-4$ and 4-8 frequency bands (Fig. 7b). The most significant one was observed in the $0-4$ bands with a correlation value of 0.85 during May 18-May 26. The phase angle denoted that the COVID-19 series was ahead of the MinT series during that time. COVID-19 case series did

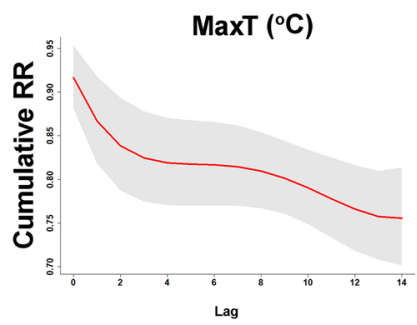

ws $(\mathrm{Km} / \mathrm{h})$

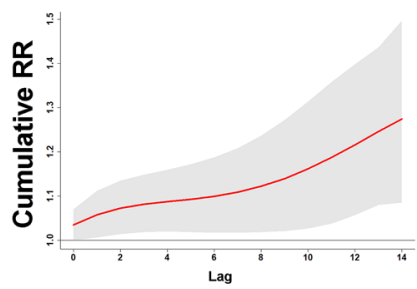

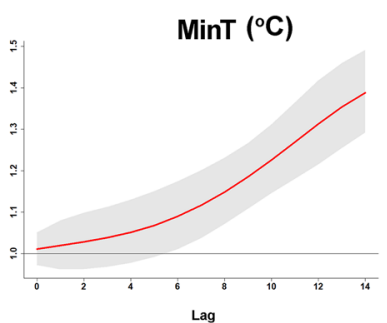

RH (\%)

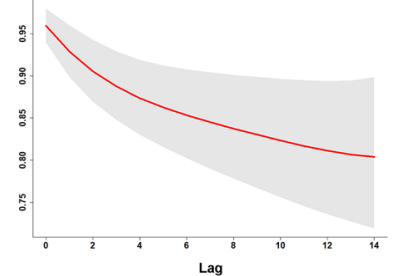

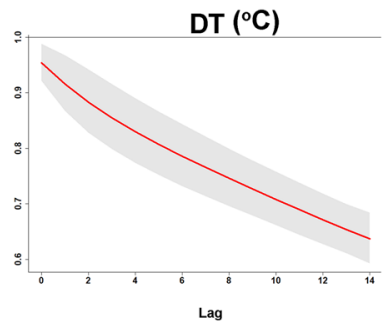

$\mathrm{AH}\left(\mathbf{g} / \mathrm{m}^{3}\right)$

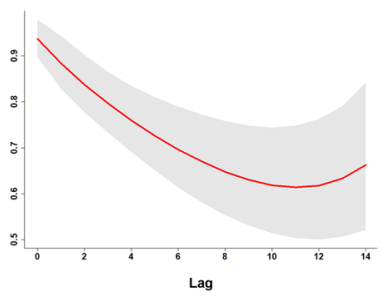

Fig. 6 Cumulative effects of maximum temperature (MaxT), minimum temperature (MinT), diurnal temperature (DT), wind speed (WS), relative humidity (RH), and absolute humidity (AH) over 14 days. The $\mathrm{Y}$ lab denotes the value of relative risk (RR); the X lab indicates the value of relevant parameters. The red lines denote mean RR, and the gray regions represent $95 \%$ CIs. The black vertical line indicates the medians of the meteorological variables, respectively 

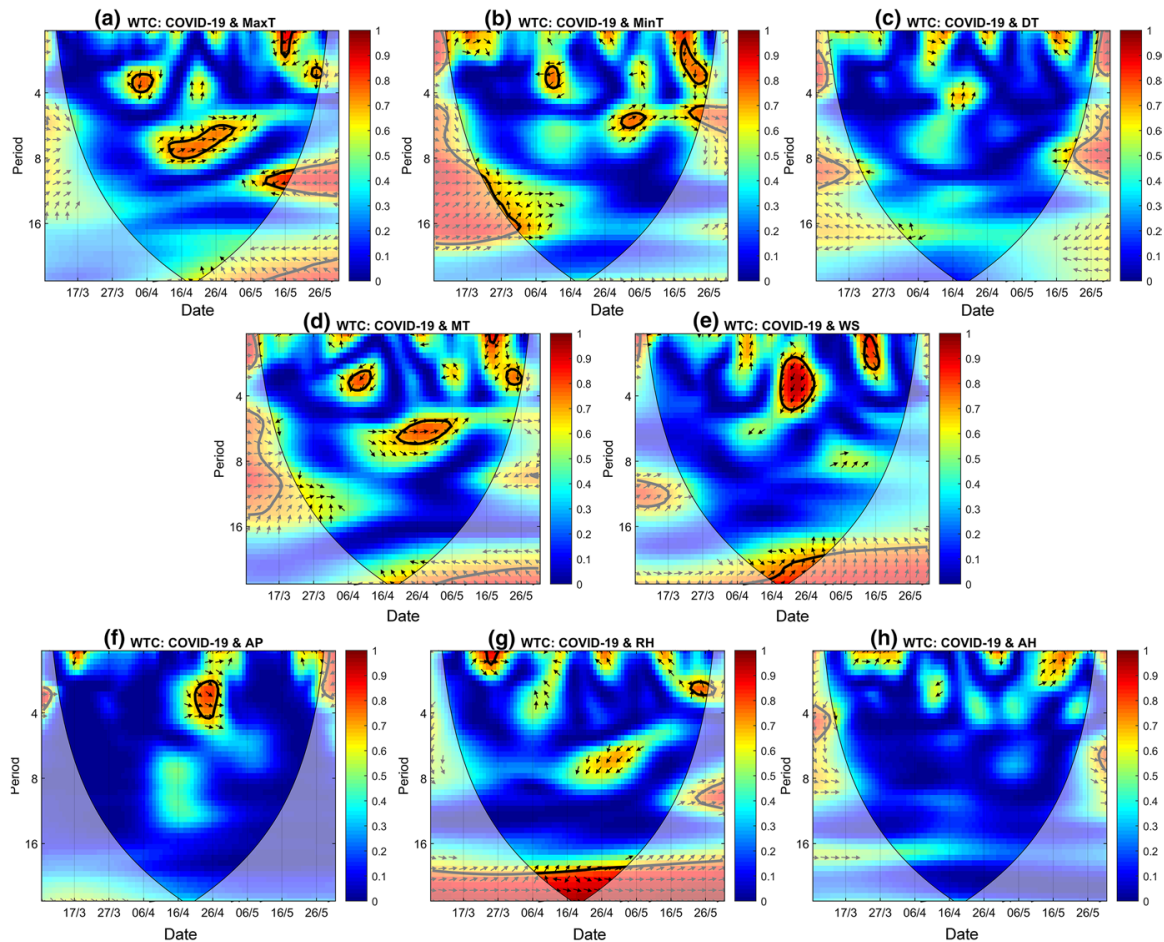

Fig. 7 Wavelet coherence (WTC) between COVID-19 confirmed case series with MaxT (a), MinT (b), DT (c), MT (d), WS (e), AP (f), RH (g) and AH (h). (The thick black cone-shaped contours show the $95 \%$ significance level, and the black line is the cone of influence. " $\rightarrow$ " denotes that the two series are in phase, while "๘" means anti-phase relationship; " $\downarrow$ " indicates that the COVID-19 confirmed case series is ahead

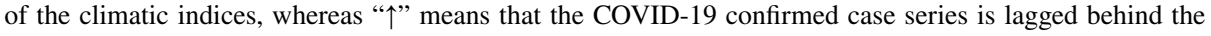
climatic indices.)

not have any significant coherence with diurnal temperature series (Fig. 7c) while MT had multiple significant coherence bands within the 0-4 and 4-8 frequency bands (Fig. $7 \mathrm{~d}$ ). The largest of them occurred at the 4-8 bands during April 19-May 6 periods with an inphase relationship. Multiple coherence bands also occurred between the COVID-19 and WS series (Fig. 7e). The most significant coherence occurred with a variation of 2-5 periods from April 18 to April 28 where the COVID-19 series was ahead of the WS series. WTC between COVID-19 and AP (Fig. 7f) series elucidated a significant in-phase relationship with a variation of 2-4.3 period during April 20-April 28. COVID-19 and RH (Fig. $7 \mathrm{~g}$ ) exhibited a very long coherence throughout the period at the most exterior band. But most of the areas with coherence were outside the cone of influence. During the April 8-May 1 period, COVID-19 and RH series were having an in-phase relationship at the exterior band. For the AH series (Fig. 7h), no significant coherence was observed with the COVID-19 series.

Among the temperature parameters, MaxT showed greater significance in WTC, and among the remaining parameters, WS and AP showed greater significance compared to the other climatic parameters. So, we aimed to examine the standalone coherence of these 
parameters while controlling the common influence of the other parameter at a time using partial wavelet coherence (PWC).

Figure $8 \mathrm{a}$ depicts the PWC between COVID-19 confirmed cases and the MaxT series while minimizing the common effects of WS. If we compare the result with the WTC between COVID-19 and MaxT (Fig. 4a), we can see that similar coherence bands appeared, which indicated that the WS did not influence the coherence between COVID-19 and MaxT, and MaxT had a significant standalone coherence with COVID-19 confirmed cases. PWC between COVID-19 and WS (Fig. 8b) showed a slight difference in the result than that of the WTC result (Fig. 7e) while taking out the common effects of MaxT. A new coherence band appeared within the 0-4 band stretched from April 7 to April 10, 2020, while a coherence band during the May 13-May 16 period diminished. It indicates that MaxT had a slight influence on the coherence between COVID-19 and WS, and WS also had a standalone coherence with COVID-19. Figure 8c elicits the PWC between COVID19 and MaxT series while controlling the common effects of AP. The size of the resonance circle increased at the 0-4 frequency band while it decreased at the 4-8 frequency band, indicating that AP affected the coherence between COVID-19 and MaxT. Figure 8d represents the PWC between COVID-19 and AP series while controlling the common effect of MaxT. Compared to WTC between COVID-19 and AP (Fig. 7f), the size of the coherence band decreased, indicating that MaxT had influenced their coherence. A new coherence band appeared for the PWC between COVID-19 and WS (Fig. 8e) while the common effects of AP were eliminated. The size of the coherence band also changed from the WTC (Fig. 7e) between these two variables, suggesting that WS had a greater standalone coherence with COVID-19 while the effect of AP was eliminated. In contrast, no coherence band appeared between COVID-19 and AP (Fig. 8f) when the common effects of WS were minimized, indicating that WS had a substantial impact on the coherence between COVID-19 and AP.

\subsection{Contact transmission and reproduction factor}

Previous studies indicate that the $R_{\mathrm{o}}$ of COVID-19 2 to 2.5, somewhat less than 3. For that reason, we considered $R_{\mathrm{o}}$ values less than 3 as the marginal range of reproduction and contact transmission is low. Results were greater than 10 , which means $R_{\mathrm{o}}=10$ indicates an extreme level of reproduction factor and a high level of contact transmission. Our study period was 45 days; 3 phases of 15 days were divided into R1, R2 and R3, respectively. Generally, COVID-19 symptoms take 5 to 14 days to show up in Bangladesh. As shown in Table 4, the situation is not worse so far due to low $R_{\mathrm{o}}$ values in seven climatic regions. The patient number increased the $R_{\mathrm{o}}$ almost decreased in most of the regions. The results indicate that the lower mid- to low level of contact transmission in the seven regions of Bangladesh.

\section{Discussion}

Meteorological indicators like temperature, humidity, wind speed and air pressure have been exhibited to play a vital role in the transmission of infectious diseases (Lu et al. 2020). We observed a significant effect between COVID-19 and meteorological variables. This finding is alike to results reported by Sajadi et al. (2020) from selected cities over the globe 

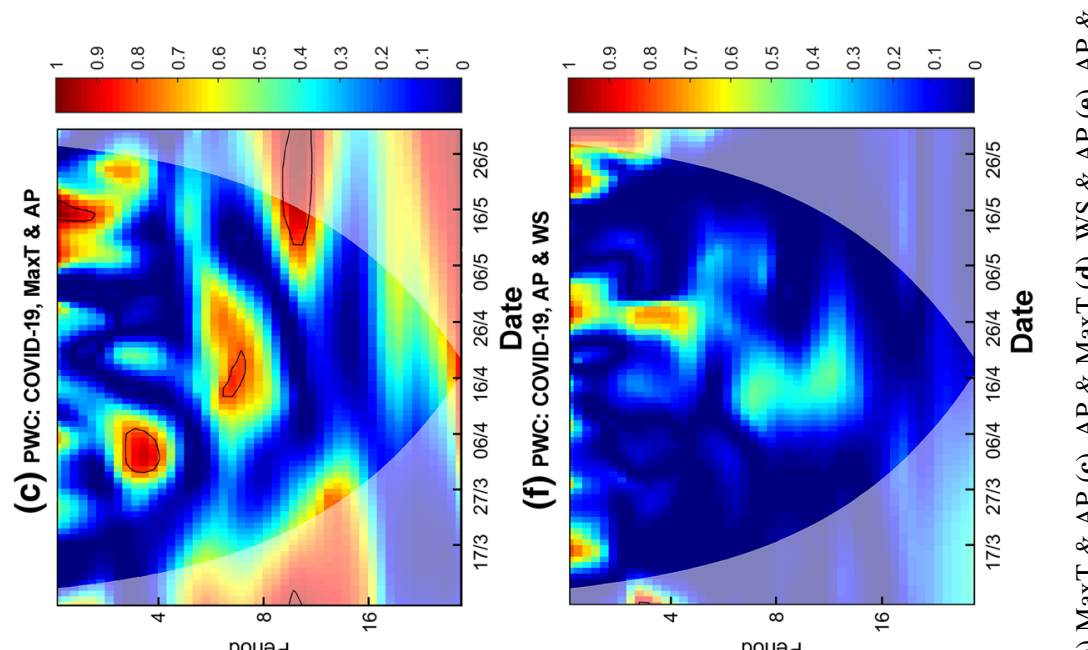

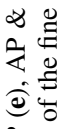

究营

皮

उ

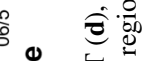

苋 㽦

$\circlearrowleft \quad \sum_{0}$

市

نิ

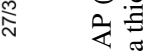

$\stackrel{m}{=} \quad \infty$
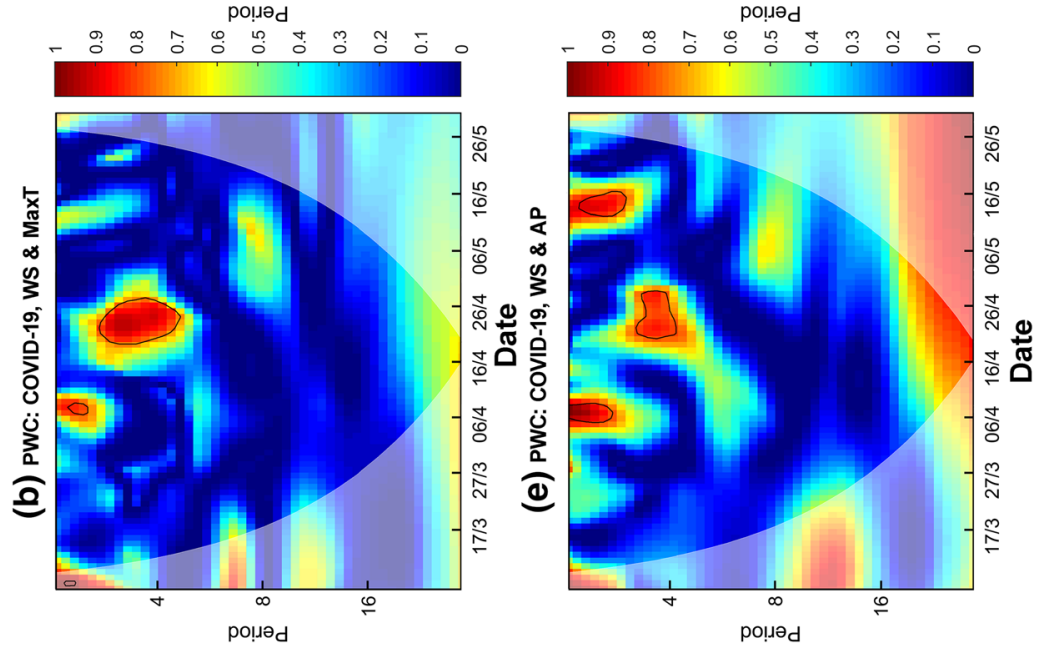

茫

ล. .

幽:
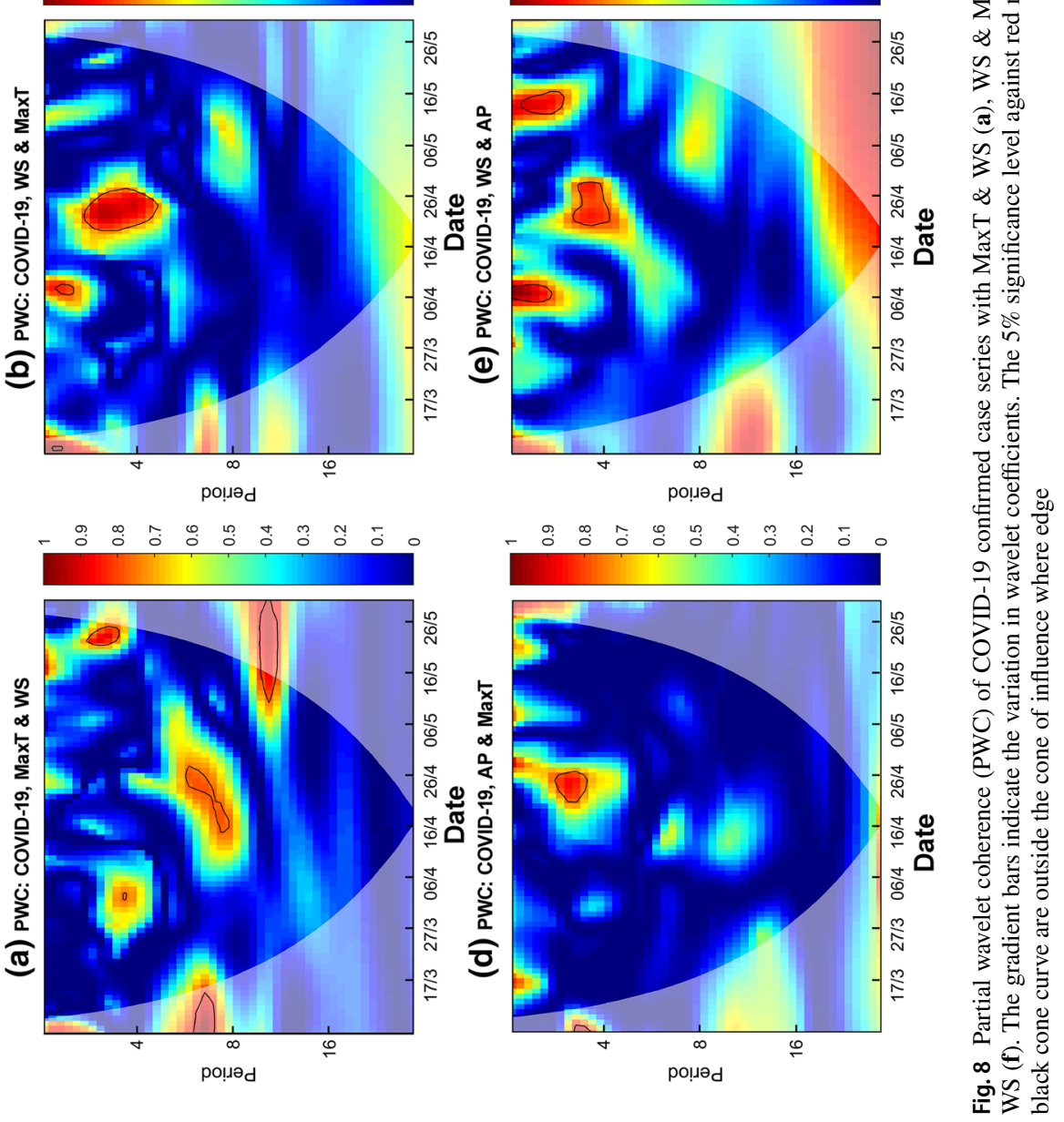
with contact transmission. Temperature, a key factor, can play a vital role in the human living system and their health regarding epidemic containment, and control (Tobías and Molina 2020). Furthermore, the wind could influence the suspension time of the coronavirus and its diffuse distancing. Our research found that the RR increased evidently, whereas the WS increased more than $21 \mathrm{~km} / \mathrm{h}$. In favor of the resuspension events, the concentration of the coronavirus might be diluted by elevated WS, which can provide a likely elucidation of this result. Temperature and wind speed a strong relationship with the COVID-19 outbreak in Bangladesh. In addition, our research found a strong effect at higher temperatures and wind speed and is supported by prior studies (Sajadi et al. 2020) and other infectious diseases (Lu et al. 2020).

Conversely, Biktasheva (2020) reported that local humidity was negatively associated with SARS-CoV-2 death in German federal states. Generally, AH shows a stronger effect than RH on the SARS-CoV-2 virus spread out (Ma et al. 2020). The transmission of influenza (Metz and Finn 2015) and SARS-CoV-1 (Chan et al. 2011) infectious diseases was strongly associated with humidity. The wind is a vital factor in SARS-CoV-2 virus transmission, which can likely regulate the dynamics of different vector-borne diseases (Ellwanger and Chies 2018). Alike in our study, WS was positively correlated with COVID-19 confirmed cases in Istanbul, Turkey (Sahin 2020) and Norway (Menebo 2020). Conversely, anti-correlation between COVID-19 and WS was found over Singapore (Pani et al. 2020) and Iran (Ahmadi et al. 2020).

Our study gives a novel insight into the association of meteorological indicators with SARS-CoV-2 in Bangladesh, but no direct associations of CT1, CT2 and CT3 with this infectious disease were observed during the study period, which may help health-care decision-makers. Outcomes from our research may assist to develop a meteorology-based warning or alert system or predicting model to accelerate the on-time response to the rise of COVID-19 outbreak (Chakraborty and Ghosh 2020; Sardar et al. 2020). For example, WS exhibited strong positive relationships with SARS-CoV-2 cases in Bangladesh; thus, the health authorities might give an alert to precaution the susceptible groups within the children and elderly people if the atmospheric prediction model is forecasting high WS values for the forthcoming months. This type of preliminary appraisal will likely provide upsurge to hypotheses for future study in epidemic dynamics of COVID-19 in Southeast Asian countries.

We employed DLNM's model in Bangladesh for the first time to identify the nonlinear effects of meteorological indicators on COVID-19 infected cases. This study revealed a nonlinear association, the RR reduced when the MaxT rose above $27^{\circ} \mathrm{C}$. This finding is consistent with an earlier DLNM research in tropical regions (Lolekha et al. 2001), who revealed a reverse impact of MaxT on the infectious disease. MinT was found as a potential risk factor for the SARS-CoV-2. The MinT changes rapidly increase the risk of respiratory coronavirus by influencing the respiratory epithelium (Graudenz et al. 2006). In such a case, people may be infected by pathogens more simply. We observed that when MinT increased $18{ }^{\circ} \mathrm{C}$, the RR of COVID-19 infection was enhanced. The possible reason is that the MinT related to a monsoonal rainy day, which stimulated people, indoor activity and increased the RR of COVID-19 spread by airdrop and closed contact. Meanwhile, the profound effect of MinT was found to raise the RR of SARS-CoV-2 spread at various lag days.

The effect of humidity on COVID-19 incidence was prominent. The RR increased apparently, whereas the RH increased more than $46 \%$ and $\mathrm{AH}$ enhanced $23 \mathrm{~g} / \mathrm{m}^{3}$. Humidity demonstrated a nonlinear dose-response effect on COVID-19 transmission followed by MinT and wind speed. A similar association between variability in $\mathrm{RH}$ and the incidence of COVID-19 outbreak is well documented in the literature (Luo et al. 2013; Shi et al. 2020; 


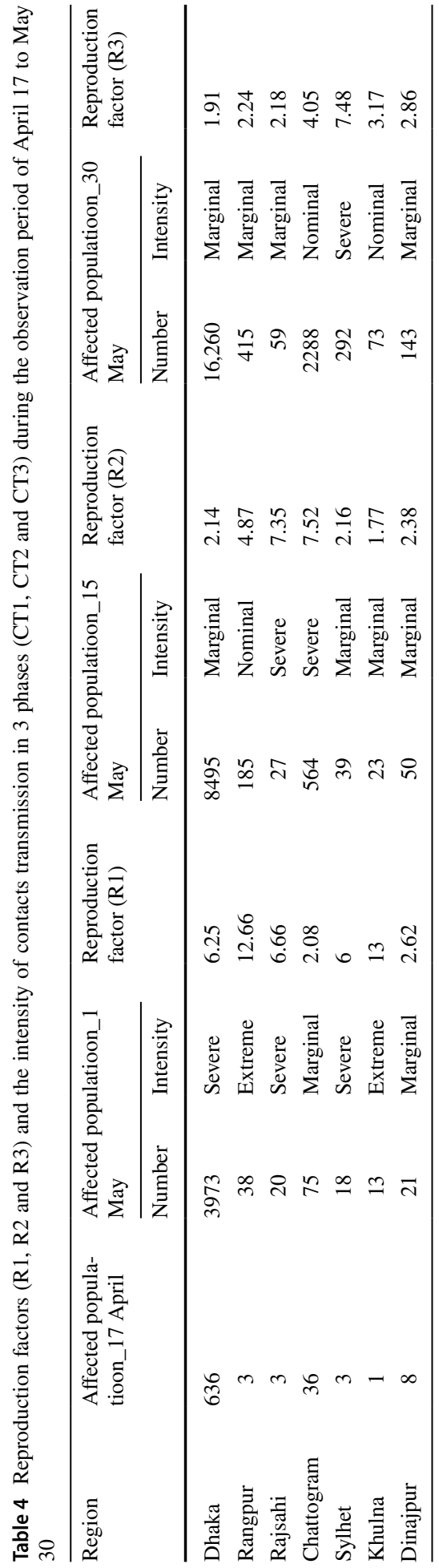


Oliveiros et al. 2020). Similar to our study, Xie and Zhu (2020) found a positive strong association between MT and the COVID-19 pandemic cases, in 122 cities from China. On the other hand, low temperature and humidity were probably to enhance the SARS-CoV-2 transmission from January 20 to March 2, 2020, in 130 Chinese cities (Liu et al. 2020). Unlike these earlier studies, no relationship between COVID-19 outbreak and temperature in Chinese cities was observed by Yao et al. (2020). Méndez-Arriaga (2020) highlighted the negative relationships of temperature with COVID-19 positive cases in the capital city of Mexico and found that MT nearly $25.95{ }^{\circ} \mathrm{C}$ and mean rainfall about $8.74 \mathrm{~mm}$ can suppress the local SARS-CoV-2 onset outbreak. A contrary association between temperatures and COVID-19 spread out was observed by Tobías and Molina (2020) in Barcelona, Spain. Similarly, a reverse but significant relationship between temperature and COVID-19 cases was observed by Shi et al. (2020) in China and reported that temperature is a key driver of the COVID-19 transmission. Bi et al. (2007) also claimed that the opposite association between temperature and SARS-CoV-1 outbreak was found. MinT can favor the advancement of SARS-CoV-2 in the early stage of the pandemic (Holtmann et al. 2020). A significant relationship between MT and COVID-19 outbreak was detected in Jakarta, Indonesia (Tosepu et al. (2020). Bashir et al. (2020) found a direct relationship with the elevated temperatures predicting elevated COVID-19 positive cases.

Overall, the wavelet analysis confirmed the results of Pearson's correlation analysis. Results demonstrated that a rise in MaxT, and AP, along with a decrease in WS served as a driving role in suppression of the COVID-19 outbreak in Bangladesh. This finding is similar to the studies by Ma et al. (2020), who claimed that a rise in temperature may assist to limit the COVID-19 outbreak, however, contrary to recent works of Iqbal et al. (2020) from Wuhan, China. The main reason for conflicting outcomes is that the geographical scope and diverse climatic regions may be affected in their results.

The $R_{\mathrm{o}}$ in Bangladesh comparatively low, but the limited number of tests did not result in these low values. $R_{\mathrm{o}}$ fractionated result of the COVID-19 positive patient and the number of tests remains almost the same during the observation period. This indicates the better immunity system of the people of Bangladesh, along with the sub-continent rather than the humid climatic region although some climatic factors showed significant outcomes. Zhang et al. (2020) applied $R_{\mathrm{o}}$ in China that presumed $R_{\mathrm{o}}$ value 2.7, indicating high contamination. In that case, one affected person can infect more than 30 persons, where a strong invention case scenario stops contamination to the exact $R_{\mathrm{o}}$ value or less regarding the World Health Organization as $R_{\mathrm{o}}$ of COVID-19 is between 2 and 2.5. (WHO 2020b). WHO stated that one individual can spread the virus from 1.5 to 3.5 per person dependent on various factors including population density, lockdown and isolation maintenance, government functions, climate and mass awareness medical condition of the individuals (WHO 2020a). Later, WHO published a report on May 20, 2020, and they corrected the value and declared the contamination rate varied from 2 to 2.5 (WHO 2020b).

Sahafizadeh and Sartoli. (2020) estimated the $R_{\mathrm{o}}$ for Iran and found that the first outbreak value was 4.86 , which was after the $14^{\text {th }}$ day first the patient was detected. They determined the second-week value was 4.5, and the third and fourth weeks were 4.2 and 2.1 consecutively. Another study by Zhao et al. (2020) found the estimated $R_{\mathrm{o}}$ value of 2.24 to 3.58. They used quarterly data to determine the change in the number of patients and compare them to the $R_{\mathrm{o}}$ actual values. Wu et al. (2020) used similar approaches and found the estimated $R_{\mathrm{o}}$ value of 2.68. Although the number is rising rapidly in Bangladesh, the result confirms that if Bangladesh government did not force the intervention measure in time, the situation will worsen. The current $R_{\mathrm{o}}$ of Bangladesh is reasonably compared to 
Southeast Asia, even the world. The climatic region is related to the transmission of coronavirus. The virus is mobile, can pass about 6 feet through the air and can sustain a long period in weather; some factors like wind speed and humidity require some investigation. The variation in climatic factors differs from the transmission, and affection rate proves the statement.

Although this research provides strong evidence of the relationship of meteorological indicators with COVID-19 cases, the following limitations are found. First, more parameters such as air quality, rainfall and solar radiation must perform a detailed study as COVID-19 is an infectious disease. Second, as the COVID-19 is an infectious disease and initially exaggerated by population dynamics, health-care facilities (Shammi et al. 2020a), social distancing and human isolation, and individual' immunity and tolerance, more parameters must conduct a detailed study (Shammi et al. 2020b). Third, the epidemiological data including gender and age group population require to be conducted to explore the sensitive group. Fourth, the data regarding individual hygiene, including hand washing and utilization of hand sanitizer, require to be examined more obviously. Finally, the SARS$\mathrm{CoV}-2$ outbreak is affected by population density, mass behavior, immunity mechanisms, and virus infection (Cory 2015), and environmental factors (Menebo 2020).

The epidemiological data required to maintain more cautiously and systematically to differentiate the number of infected cases and local outbreak rates in further investigation. However, the mixed findings on the influence of air pressure on the COVID-19 outbreak underscore the need for more research over various geographic settings and longer time series dataset. Further research works should be considered such as daily testing rate and other social and environmental factors as control parameters for investigating the relationship between meteorological variables and COVID-19 confirmed cases. Additionally, datasets for SARS-CoV-2 vaccination and human serum antibody levels were still unavailable. Thus, more research should be taken into consideration the vaccination variables.

\section{Conclusions}

Our results showed that MinT and WS have a positive significant correlation with the number of COVID-19 confirmed cases, while SARS-CoV-2 revealed significant anti-correlation with MaxT, DT and AP. COVID-19 transmission was observed to be favored by high $\mathrm{AH}$ than RH settings in Bangladesh. The coupling influence of meteorological indicators on COVID-19 cases may be profound in Bangladesh. MinT and WS demonstrated a significant nonlinear dose-response cumulative effect on COVID-19 transmission followed by AH, which is contrary to MaxT and DT. Based on the Pearson correlation and wavelet coherence results, it can be concluded that an increase in MaxT and AP and a decrease in WS could aid in the containment of COVID-19 transmission in Bangladesh. The PWC findings suggested that MaxT and WS had a standalone influence on the SARS-CoV-2 spreading and these parameters were also influencing the relationship between COVID-19 cases and other meteorological parameters. There was no direct association between CT1, CT2 and CT3 with the spreading of the COVID-19. The results of low $R_{\mathrm{o}}$ values indicate a low outbreak of COVID-19 in Bangladesh. This research gives useful information for public health-care decision-makers to insights into the meteorological dependency of SARS-CoV-2 across Bangladesh. Effective measures such as zone-based lockdown should be taken to suppress the COVID-19 outbreak and further spreading. 
Acknowledgements We are grateful to the anonymous reviewer for providing critical comments to improve the quality of the manuscript. We acknowledge the Bangladesh Meteorological Department (BMD) for providing the weather data sets. We also acknowledge the frontline fighter, doctors, nurses and police combat COVID-19 in Bangladesh.

Funding This work was supported by Researchers Supporting Project number (RSP-2020/100), King Saud University, Riyadh, Saudi Arabia.

Data availability Data are available on the reasonable request to corresponding author.

\section{Compliance with ethical standards}

Conflict of interest The authors declare that they have no conflict of interest.

Ethical approval Not applicable.

\section{References}

Ahmadi, M., Sharifi, A., Dorosti, S., Ghoushchi, S. J., \& Ghanbari, N. (2020). Investigation of effective climatology parameters on COVID-19 outbreak in Iran. Science of the Total Environment, 728, 138705.

Auler, A. C., Cássaro, F. A. M., da Silva, V. O., \& Pires, L. F. (2020). Evidence that high temperatures and intermediate relative humidity might favor the spread of COVID-19 in tropical climate: A case study for the most affected Brazilian cities. Science of the Total Environment, 729, 139090. https://doi. org/10.1016/j.scitotenv.2020.139090.

Bashir, F. M., Ma, B., Komal, B., Bashir, M. A., Tan, D., \& Bashir, M. (2020). Correlation between climate indicators and COVID-19 pandemic in New York, USA. Science of the Total Environment, 728, 138835

Bi, P., Wang, J., \& Hiller, J. (2007). Weather: driving force behind the transmission of severe acute respiratory syndrome in China? Internal Medicine Journal, 37, 550-554. https://doi.org/10.111 1/j.1445-5994.2007.01358.x.

Biktasheva, I. V. (2020). Role of a habitat's air humidity in Covid-19 mortality. Science of the Total Environment. https://doi.org/10.1016/j.scitotenv.2020.138763.

Bodrud-Doza, M., Shammi, M., Bahlman, L., Islam, A. R. M. T., \& Rahman, M. M. (2020). Psychosocial and socio-economic crisis in Bangladesh due to COVID-19 pandemic: A perception-based assessment. Frontiers in Public Health, 8, 341. https://doi.org/10.3389/fpubh.2020.00341.

Briz-Redón, A., \& Serrano-Aroca, A. (2020). A spatio-temporal analysis for exploring the effect of temperature on COVID-19 early evolution in Spain. Science of the Total Environment, 728, 138811. https:// doi.org/10.1016/j.scitotenv.2020.138811.

Casanova, L. M., Jeon, S., Rutala, W. A., Weber, D. J., \& Sobsey, M. D. (2010). Effects of air temper- ature and relative humidity on coronavirus survival on surfaces. Applied and Environment Microbiology, 76, 2712-2717.

Chakraborty, T., \& Ghosh, I. (2020). Real-time forecasts and risk assessment of novel coronavirus (COVID19) cases: A data-driven analysis. Chaos, Solitons \& Fractals, 135, 109850. https://doi.org/10.1016/j. chaos.2020.109850.

Chan, K., Peiris, J., Lam, S., Poon, L., Yuen, K., \& Seto, W. (2011). The effects of temperature and relative humidity on the viability of the SARS coronavirus. Archives of Virology. https://doi. org/10.1155/2011/734690.

Chen, N., Zhou, M., Dong, X., Qu, J., Gong, F., Han, Y., et al. (2020). Epidemiological and clinical characteristics of 99 cases of 2019 novel coronavirus pneumonia in Wuhan, China: a descriptive study. Lancet, 395, 507-513. https://doi.org/10.1016/s0140-6736(20)30211-7.

Cortegiani, A., Ingoglia, G., Ippolito, M., Giarratano, A., \& Einav, S. (2020). A systematic review on the efficacy and safety of chloroquine for the treatment of COVID-19. Journal of Critical Care, 57, 279283. https://doi.org/10.1016/j.jcrc.2020.03.005.

Cory, J. S. (2015). Insect virus transmission: different routes to persistence. Current Opinion in Insect Science, 8, 130-135. https://doi.org/10.1016/j.cois.2015.01.007. 
Dai, Q., Ma, W., Huang, H., Xu, K., Qi, X., Yu, H., et al. (2018). The effect of ambient temperature on the activity of influenza and influenza like illness in Jiangsu Province, China. Science of the Total Environment, 645, 684-691. https://doi.org/10.1016/j.scitotenv.2018.07.065.

Ellwanger, J. H., \& Chies, J. A. B. (2018). Wind: A neglected factor in the spread of infectious diseases. The Lancet Planetary Health, 2, e475. https://doi.org/10.1016/S2542-5196(18)30238-9.

Gasparrini, A., Armstrong, B., \& Kenward, M. G. (2010). Distributed lag non-linear models. Statistics in Medicine, 29(21), 2224-2234. https://doi.org/10.1002/sim.3940.

Graudenz, G. S., Landgraf, R. G., Jancar, S., Tribess, A., Fonseca, S. G., Fae, K. C., et al. (2006). The role of allergic rhinitis in nasal responses to sudden temperature changes. The Journal of Allergy and Clinical Immunology, 118, 1126-1132. https://doi.org/10.1016/j.jaci.2006.07.005.

Holtmann, M., Jones, M., Shah, A., \& Holtmann, G. (2020). Low ambient temperatures are associated with more rapid spread of COVID-19 in the early phase of the endemic. Environmental Research, 186, 109625. https://doi.org/10.1016/j.envres.2020.109625.

Institute of Epidemiology, Disease Control and Research (IEDCR). (2020). Covid-19 status Bangladesh. Retrieved April 12, 2020, from https://www.iedcr.gov.bd/.

Iqbal, N., Fareed, Z., Shahzad, F., He, X., Shahzad, U., \& Lina, M. (2020). Nexus between COVID-19, temperature and exchange rate in Wuhan City: New findings from Partial and Multiple Wavelet Coherence. Science of The Total Environment, 728, 138916.

Islam, A. R. M. T., Shen, S., \& Yang, S. (2018). Predicting design water requirement of winter paddy under climate change condition using frequency analysis in Bangladesh. Agric Water Management, 195, 58-70. https://doi.org/10.1016/j.agwat.2017.10.003037.

Li, Q., Guan, X., Wu, P., Wang, X., Zhou, L., et al. (2020). Early transmission dynamics in Wuhan, China, of novel coronavirus-infected pneumonia. The New England Journal of Medicine. https://doi. org/10.1056/NEJMoa2001316.

Linton, N. M., Kobayashi, T., Yang, Y., et al. (2020). Incubation period and other epidemiological characteristics of 2019 novel coronavirus infections with right truncation: A statistical analysis of publicly available case data. Journal of Clinical Medicine, 9, 538.

Liu, J., Zhou, J., Yao, J., Zhang, X., Li, L., et al. (2020). Impact of meteorological factors on the COVID-19 transmission: A multi-city study in China. Science of the Total Environment, 726, 138513. https://doi. org/10.1016/j.scitotenv.2020.138513.

Lolekha, S., Tanthiphabha, W., Sornchai, P., et al. (2001). Effect of climatic factors and population density on varicella zoster virus epidemiology within a tropical country. American Journal of Tropical Medicine and Hygiene, 64, 131-136. https://doi.org/10.4269/ajtmh.2001.64.131.

Lowe, R., Gasparrini, A., Van Meerbeeck, C. J., et al. (2018). Nonlinear and delayed impacts of climate on dengue risk in Barbados: A modelling study. PLoS Medicine, 15, e1002613. https://doi. org/10.1371/journal.pmed.1002613.

Lu, J., Gu, J., Li, K., Xu, C., Su, W., Lai, Z., et al. (2020). COVID-19 outbreak associated with air conditioning in restaurant, Guangzhou, China. Emerging Infectious Diseases. https://doi.org/10.3201/ eid2607.200764.

Luo, Y., Zhang, Y., Liu, T., Rutherford, S., et al. (2013). Lagged effect of diurnal temperature range on mortality in a subtropical megacity of China. PLoS ONE, 8(2), e55280.

Ma, Y., Zhao, Y., Liu, J., He, X., Wang, B., Fu, S., et al. (2020). Effects of temperature variation and humidity on the death of COVID-19 in Wuhan, China. Science of The Total Environment, 724, 138226. https://doi.org/10.1016/j.scitotenv.2020.138226.

Méndez-Arriaga, F. (2020). The temperature and regional climate effects on communitarian COVID19 contagion in Mexico throughout phase 1. Science of the Total Environment. https://doi. org/10.1016/j.scitotenv.2020.139560.

Menebo, M. M. (2020). Temperature and precipitation associate with Covid-19 new daily cases: A correlation study between weather and Covid-19 pandemic in Oslo, Norway. Science of the Total Environment, 737, 139659. https://doi.org/10.1016/j.scitotenv.2020.139659.

Metz, J. A., \& Finn, A. (2015). Influenza and humidity-Why a bit more damp may be good for you! Journal of Infection, 71, S54-S58. https://doi.org/10.1016/j.jinf.2015.04.013.

Neher, R. A., Dyrdak, R., Druelle, V., Hodcrof, E. B., \& Albert, J. (2020). Potential impact of seasonal forcing on a SARS-CoV-2 pandemic. Swiss Medical Weekly, 150, w20224. https://doi.org/10.4414/ smw.2020.20224.

Oliveiros, B., Caramelo, L., Ferreira, N. C., \& Caramelo, F. (2020). Role of temperature and humidity in the modulation of the doubling time of COVID-19 cases. medRxiv. https://doi. org/10.1101/2020.03.05.20031872. 
Pani, S. K., Lin, N. H., \& RavindraBabu, S. (2020). Association of COVID-19 pandemic with meteorological parameters over Singapore. Science of the Total Environment. https://doi.org/10.1016/j.scito tenv.2020.140112.

Prata, D. N., Rodrigues, W., \& Bermejo, P. H. (2020). Temperature significantly changes COVID19 transmission in (sub)tropical cities of Brazil. Science of the Total Environment. https://doi. org/10.1016/j.scitotenv.2020.138862.

Rahman, M. S., \& Islam, A. R. M. T. (2019). Are precipitation concentration and intensity changing in Bangladesh overtimes? Analysis of the possible causes of changes in precipitation systems. Science of the Total Environment, 690, 370-387. https://doi.org/10.1016/j.scitotenv.2019.06.529.

Runkle, J. D., Sugg, M. M., Leeper, R. D., Rao, Y., Matthews, J. L., \& Rennie, J. J. (2020). Short-term effects of specific humidity and temperature on COVID-19 morbidity in select US cities. Science of the Total Environment, 740, 140093. https://doi.org/10.1016/j.scitotenv.2020.140093.

Sahafizadeh, E., \& Sartoli, S. (2020). Estimating the reproduction number of COVID-19 in Iran using epidemic modeling. Epidemiology. https://doi.org/10.1101/2020.03.20.20038422.

Sahin, M. (2020). Impact of weather on COVID-19 pandemic in Turkey. Science of the Total Environment, 728, 138810. https://doi.org/10.1016/j.scitotenv.2020.138810.

Sajadi, M. M., et al. (2020). Temperature and latitude analysis to predict potential spread and seasonality for COVID-19. SSRN 3550308.

Sardar, T., Ghosh, I., Rodó, X., \& Chattopadhyay, J. (2020). A realistic two-strain model for MERSCoV infection uncovers the high risk for epidemic propagation. PLOS Neglected Tropical Diseases, 14, e0008065. https://doi.org/10.1371/journal.pntd.0008065.

Shammi, M., Bodrud-Doza, Md, Islam, A R M d T, \& Rahman, M d M. (2020a). Psychosocial, and socio-economic crisis in Bangladesh due to COVID-19 pandemic: A perception-based assessment. Heliyon, 6(5), e04063.

Shammi, M., Bodrud-Doza, M., Islam, A. R. M. T., \& Rahman, M. M. (2020b). Strategic assessment of COVID-19 pandemic in Bangladesh: Comparative lockdown scenario analysis, public perception, and management for sustainability. Environment, Development, Sustainability.. https://doi. org/10.1007/s10668-020-00867-y.

Shi, P., Dong, Y., Yan, H., Li, X., Zhao, C., Liu, W., et al. (2020). The impact of temperature and absolute humidity on the coronavirus disease 2019 (COVID-19) outbreak-Evidence from China. medRxiv. https://doi.org/10.1101/2020.03.22.20038919.

Snyder, R. L. (2005). Humidity conversion. Davis, University of California: Biometeorology Program.

Sobral, M. F. F., Duarte, G. B., da Penha Sobral, A. I. G., et al. (2020). Association between climate variables and global transmission oF SARS-CoV-2. Science of the Total Environment. https://doi. org/10.1016/j.scitotenv.2020.138997.

Tobías, A., \& Molina, T. (2020). Is temperature reducing the transmission of COVID-19? Environmental Research, 186, 109553. https://doi.org/10.1016/j.envres.2020.109553.

Tosepu, R., Gunawan, J., Effendy, D. S., Ahmad, L. O. A. I., Lestari, H., Bahar, H., et al. (2020). Correlation between weather and Covid-19 pandemic in Jakarta, Indonesia. Science of the Total Environment, 725, 138436. https://doi.org/10.1016/j.scitotenv.2020.138436.

Wacker, M., \& Holick, M. F. (2013). Sunlight and Vitamin D: A global perspective for health. Dermatoendocrinol., 5(1), 51-108. https://doi.org/10.4161/derm.24494.

WHO. (2020a). Coronavirus disease 2019 (COVID-19). Situation report-51. https://www.who.int/docs/ default-source/coronaviruse/situationreports/20200311-sitrep-51-covid-19.pdf?sfvrsn=1ba62e57_10. Accessed 30 Mar 2020.

WHO. (2020b). Coronavirus disease 2019 (COVID-19). Situation report-66, March 26, 2020. https://www. who.int/docs/default-source/coronaviruse/situationreports/20200326-sitrep-66-covid-19.pdf?sfvrs $\mathrm{n}=9 \mathrm{e} 5 \mathrm{~b} 8 \mathrm{~b} 48 \_2$. Accessed 30 Mar 2020.

Wu, J. T., Leung, K., \& Leung, G. M. (2020). Now casting and forecasting the potential domestic and international spread of the 2019-nCoV outbreak originating in Wuhan, China: A modelling study. Lancet, 395(10225), 689-697.

Xie, J., \& Zhu, Y. (2020). Association between ambient temperature and COVID-19 infection in 122 cities from China. Science of the Total Environment, 724, 138201. https://doi.org/10.1016/j.scito tenv.2020.138201.

Yao, Y., Pan, J., Liu, Z., Meng, X., Wang, W., Kan, H., et al. (2020). No association of COVID-19 transmission with temperature or UV radiation in Chinese cities. European Respiratory Journal. https://doi. org/10.1183/13993003.00517-2020.

Yu, G., Li, Y., Cai, J., Yu, D., Tang, J., Zhai, W., et al. (2019). Short-term effects of meteorological factors and air pollution on childhood hand-foot-mouth disease in Guilin, China. Science of the Total Environment, 646, 460-470. https://doi.org/10.1016/j.scitotenv.2018.07.329. 
Zhang, S., et al. (2020). Estimation of the reproductive number of novel coronavirus (COVID-19) and the probable outbreak size on the Diamond Princess Cruise ship: A data-driven analysis. International Journal of Infectious Diseases, 93, 201-204.

Zhao, S., Lin, Q., \& Ran, J. (2020). Preliminary estimation of the basic reproduction number of novel coronavirus (2019-nCoV) in China, from 2019 to 2020: A data-driven analysis in the early phase of the outbreak. International Journal of Infectious Diseases, 92, 214-217. https://doi.org/10.1016/j. ijid.2020.01.050.

Publisher's Note Springer Nature remains neutral with regard to jurisdictional claims in published maps and institutional affiliations.

\section{Affiliations}

Abu Reza Md. Towfiqul Islam ${ }^{1}$ (D) Md. Hasanuzzaman ${ }^{1} \cdot$ Md. Abul Kalam Azad ${ }^{1}$. Roquia Salam ${ }^{1}$ - Farzana Zannat Toshi ${ }^{2}$ - Md. Sanjid Islam Khan ${ }^{1}$. G. M. Monirul Alam ${ }^{3}$. Sobhy M. Ibrahim ${ }^{4}$

1 Department of Disaster Management, Begum Rokeya University, Rangpur 5400, Bangladesh

2 Department of Statistics, Begum Rokeya University, Rangpur 5400, Bangladesh

3 Department of Agribusiness, Bangabandhu Sheikh Mujibur Rahman Agricultural University, Dhaka, Bangladesh

4 Department of Biochemistry, College of Science, King Saud University, P.O. Box 2455, Riyadh 11451, Saudi Arabia 